Published in Arts and Humanities in Higher Education Online first on 24

December 2019 at https://doi.org/10.1177/1474022219896832

\title{
How do we integrate skills and content in classics? An inquiry into students' use of sources
}

\author{
Karl A Goodwin and Kathleen M. Quinlan \\ University of Kent
}

\begin{abstract}
Engagement with primary sources is a key feature of arts and humanities subjects, particularly classics and ancient history. Recent instructional trends emphasise integrating skills with content, particularly in the first year of higher education. We investigate how successfully first-year university students used a variety of sources in an integrated skills and content course, through analysis of 84 final essays. Most students used four to nine sources in a 1500 word essay, but only one type of ancient source. The findings express the need to move from debates about whether to integrate skills or not, to greater discuss how key discipline-specific skills are integrated into content-based courses. Cognitive apprenticeship theory, and a thematic approach used in museum education, are used to reflect on the findings and discuss how teachers might better support students in this key aspect of the discipline.
\end{abstract}

Keywords: Cognitive apprenticeship theory, transition, classical students, ancient history, teaching, source engagement, college

\section{Introduction}

The transition between school and university brings many challenges for new undergraduate students and their teachers (Baker, 2017: 406; Briggs, Clark and Hall, 2012: 3; Ferreira, 2018: 1; Perry and Allard, 2003: 74). In classical studies, and ancient history, first-year university students encounter a greater emphasis on critical engagement with a wider array of sources than previously experienced. ${ }^{1}$

\footnotetext{
${ }^{1}$ Throughout this paper, classical studies and classics have been used interchangeably to refer to the study of ancient Greece and Rome.
} 
Engagement with primary sources is a sine qua non of arts and humanities subjects generally. Many students studying history at undergraduate degree level struggle with critical engagement with literature (Booth, 2003: 2005; Skinner, 2014: 367). However, the challenge is more acute in the interdisciplinary field of classics and ancient history. Students of the classical period must make sense of various forms of literature, fragmentary texts, historical and legal documents, art, and material culture. The limited surviving evidence from the ancient past may mean students can examine all available primary source material related to a given problem or question, giving them a unique opportunity to formulate their own judgements on an issue or question. Thus being able to interpret and synthesise a variety of sources is a central skill for students to enable them to develop their own interpretations of the ancient past (Quality Assurance Agency, 2014).

We examine how successfully students engage with relevant primary sources in their essay assignments in the first year of university. ${ }^{2}$ We then consider alternative pedagogical approaches that might enhance this key skill and contribute to the contemporary trend of integrating the teaching of skills with content in the humanities (Booth, 2005: 19; Wilson and Child, 2017: 189). To reflect on source use in teaching classics, and how this skill can be integrated more successfully, we draw on the instructional model of cognitive apprenticeship (Collins et al., 1991) and a thematic approach to the integration of skills with content. Whilst we focus on classics, the discussion is likely to be relevant to other humanities subjects, particularly the study of history, languages, and literature.

\section{The Transition from School to University in Classics}

In this paper, we focus on a key challenge faced by students in the transition from United Kingdom (UK) A-level to bachelor degree level in the field of classics and ancient

\footnotetext{
${ }^{2}$ The phrase 'primary sources' has been used synonymously with 'classical sources' throughout this paper.
} 
history, where there is a particular absence of published work (Goodman, 2017: 48). Using a methodology borrowed from Goodman (2017), this paper refers to literature from closely related subjects such as English, history and geography to contribute to understanding teaching in classics and ancient history.

Students may not be adequately prepared for the qualitatively different demands of university study after completing their A-level studies (Baker, 2017: 404, 406; Wilson and Child, 2017: 189). For example, Baker (2017) described the substantial changes in reading and writing practices between A-Levels and university in students who took English Literature at A-levels. She showed how A-level education emphasised textbook knowledge that students were expected to master and reconstruct in very particular ways for examiners, in contrast to the wider range of independent reading expected of students in university. The students in her ethnographic study focused almost entirely on textbooks, with the occasional foray into teacher- and exam-board approved "magazines" (Baker, 2017: 397). In our analysis of A-level specifications ${ }^{3}$ in classics, which are taught in translation, we find topics predominantly rely upon just two or three different primary sources as prescribed reading (AQA, 2014: 6-25; OCR, 2016: 18-58, 2018: 6-45). ${ }^{4}$ The Assessment and Qualifications Alliance's (AQA) specification for classics has a modular format separating topics into units, which reflects the structure found in universities. These units for AQA are specific to particular individuals, places, literature, and events.

Oxford Cambridge and RSA Examinations' (OCR) new A-level specification, however, provides units with some thematic titles rather than being event or source specific

\footnotetext{
${ }^{3}$ This paper uses the A-level specifications from Assessment and Qualifications Alliance (AQA) and Oxford Cambridge and RSA Examinations (OCR), two main A-level exam boards in England.

${ }^{4}$ OCR developed a new curriculum for A-level Classical Civilisation for first teaching in 2017 and first assessment in 2019. It is therefore beneficial to refer to both old and new OCR A-level specifications.
} 
(e.g. 'Love and Relationships', 'Politics of the Late Republic', and 'Invention of the Barbarian' (OCR, 2018: 6)). Graduates of OCR's new A-level specification will begin university in 2019 and may bring a different orientation than graduates of the old curriculum. Nonetheless, the prescribed literature for these thematic units are limited in diversity of type and authorship, just like the more rigid units provided by AQA. Thus, the breadth of literature listed as required sources within A-level specifications is substantially less than expected in higher education.

Alternatively, students may have studied an ancient language prior to university, and not a module that looks at specific literature or events. These students would have used ancient written sources as integral study material. OCR's A-level specification for Latin states how ancient sources from authors such as Cicero, Tacitus, and Livy are used in examination and study $(2018: 2,10,12)$. A key feature of OCR's A-level Latin course is to 'develop the language and literature skills needed to progress' into undergraduate study, and 'to gain a deeper understanding of the life and culture of the ancient world through the literature studied' (OCR 2018: 3). As such, the study of a classical language provides prospective university students with exposure to primary ancient sources, but may not cultivate attention to analysis of historical events.

In addition, there will be many students who take up classics at university with no prior experience in the subject. Individuals who have not taken A-level classics may be at some disadvantage relating to their knowledge of the classical period and overall familiarity with the range of sources used in classics. Therefore, many students will not have been introduced to the basic skills needed in classics. The demands of university are complex relative to students' past educational experiences (Alder 2016; Baker 2017), making a thoughtful reflection on discipline-sensitive pedagogy all the more important. 
Students may not be reading texts in the way expected of them in higher education. Although leading secondary school history educators emphasise the process of using primary sources to construct a coherent written argument (Wineburg, 2001, 2011), undergraduate students still may not be able to approach texts in the way those history educators advocate. British history undergraduates interviewed by Booth described how they read texts for facts, rather than interpretations and opinions expressed by the authors (2005: 17). They also tended to continue this trend when reading teacher notes and textbooks. Middendorf et al.'s interviews with academic staff in Indiana University's history department (2007) suggest that American undergraduates also read like Booth's (2005) student interviewees. The process of reading for facts rather than interpretations and arguments limits what a student gains from engaging with literature.

To increase student skills and better prepare them for university, many educational institutions offer an Extended Project Qualification (EPQ) which allows students to create, plan, and complete their own individual project within their chosen subject field which can take them beyond the standard subject specification (AQA 2019: 3). The EPQ is only optional, hence many students who come to university will not have experienced it. While numbers are growing, only 13\% of A Level students took an EPQ in 2014-15 (Gill 2016: 2). Furthermore, in 2018, school leaders expressed the opinion that EPQs are good preparation for university; however, a higher proportion stated that the EPQ was more useful for highattaining students than their low-attaining counterparts (Williamson and Vitello 2018: 30-31), suggesting a widening gap between higher and lower achieving students. As such, the EPQ offers an option for students to better prepare for university, but does not appear to currently support the majority of pre-university students.

Finally, the drop in contact hours between students and teachers reduces the amount of teacher guidance students receive at university (Ballinger, 2003: 101; Ellis, 2008; Skinner, 
2014: 370). Therefore, in their new academic setting when they are also coming to grips with these new expectations, first-year undergraduate students must rely more on their own initiative in reading academic literature, as well as forming ideas on contemporary debates in the field (Baker, 2017: 404; Ferreira, 2018: 9; Skinner, 2014: 367).

Critically engaging with a myriad of sources is therefore a key skill undergraduate students need to learn in their first year of university and continue to develop throughout their degree. Attention to this kind of skill development within disciplines is particularly important given the discipline-focused nature of UK higher education (Wingate, 2007). The Quality Assurance Agency (QAA) statement for classics and ancient history emphasises the importance of primary material (QAA, 2004: 11). The QAA benchmark statement for classics and ancient history explicitly states that a graduate will have a knowledge of a range of primary sources (QAA, 2014: 14). Furthermore, familiarity with sources has been a constant, fundamental staple of classical research. To address important subject-specific skills such as source engagement, many programmes now aim to integrate subject-specific skills training into their teaching (Wilson and Child, 2017: 189; Wingate, 2007).

In history, Booth suggests that skills training should be embedded within contentbased modules (2005: 19). Not only does this approach allow an integration of content and skills, it avoids patronising stronger students with separate units on the basics of the field. It also avoids the potential for students to de-emphasise skills units in favour of content-based units (Booth, 2005: 17). An integrated approach is thus seen as more authentic to the practice of history, and a process to which other subjects should aspire (Wingate, 2007).

In this study, we investigate how successful this skills-integration method has been in a classics module for first-year university students at Egeria University (a pseudonym), following Heiland and Rosenthal's (2013) recommendation to use local case studies to advance understanding of learning and teaching. The module design and this study were 
guided by the theory of constructive alignment (Biggs, 1996). That theory postulates that learning in higher education depends upon alignment between intended learning outcomes, teaching methods and assessment methods and criteria (Biggs, 1996). We ask how successfully the module achieved the key learning outcome of students incorporating a range of sources within their scholarly work. We explored this overarching question by examining the number, type and variety of different sources students used in the final essays of this core first year module. Thus, this investigation provides an outcomes-based evaluation of the effectiveness of this increasingly common, integrated approach to teaching skills, framed by the theory of constructive alignment (Biggs, 1996). Given the limitations we found in students' work, we also offer a substantive discussion of a possible alternative way forward to be tested in further studies.

\section{Method}

All students completed a core module with 2 hours of contact time per week, over 24 weeks focusing on the history and literature of ancient Greece and Rome at Egeria University. Four weeks in total were used as reading weeks with students encouraged to use the time to research, plan, and write assignments. Consistent with the UK QAA benchmark statement expectations (2014: 10,11,14), one of the module's intended learning outcomes states that students will, 'Draw together a wide range of sources for Greek and Roman history (legal, literary, historical [and] biographical)'. We examined students' essays to determine how successfully students integrated a variety of sources in classics in their work.

\section{Context}

Egeria University's Classical Studies undergraduate degree integrated skills training within content-based modules as recommended by Booth (2005: 19) in 2018; an initiative that was also adopted by other UK universities (Ferreira, 2018: 2; Goodman, 2017: 50). Until recently, 
undergraduates in the classics department at Egeria University participated in a classicsspecific skills module separate from a content-focused core module. That separate skillsbased module was discontinued in favour of incorporating skills development into a core content module focusing on ancient Greek and Roman history and literature ('History and Literature of Ancient Greece and Rome' (a pseudonym)). To develop classics-based intellectual skills, seminars incorporated demonstrations of these skills in published literature, discussion of multiple types of sources during teaching, content-specific inquiry-based questioning, and assignment feedback.

Egeria University's module, 'History and Literature of Ancient Greece and Rome' was taught via weekly 50 minute lectures for the entire cohort of 135 students, supplemented by weekly 50 minute seminars in groups of 19-25 students throughout the first and second terms (for a total of 24 weeks). The first 12 -week term focused on $5^{\text {th }}$ century BC Athens. The second 12-week term concentrated on specific individuals, events, and literature relating to the last century of the Roman Republic. There were seven seminar groups in term one led by three individuals, and six in the second term led by two. Contemporary to the final assignment in term two which this paper uses as a case study, there were two seminar classes led by a senior academic who convened the module. The other four seminar groups were taught by a second-year PhD student and Graduate Teaching Assistant (GTA) who had led seminars for the module in the previous year.

There were three assessments in total including two 1500 word essays. The first essay addressed $5^{\text {th }}$ century BC Greece, and the second essay addressed the period around the downfall of the Roman Republic. The third assessment was a journal article review, which relied upon students critically engaging with a piece of contemporary scholarship. Each assessment was designed to promote engagement with key ideas, figures, events, and literature. 
The Roman essay, the focus of this study, was the last of these coursework assignments, with a deadline at the end of the second term. Students worked on the essay during the second term individually, outside of class time. As the Roman essay took place at the end of the second term, students had previous experience at essay writing, and feedback on an essay from the same module. The questions set were broad, but also specified certain ancient authors, particular ancient sources, or events that are were addressed in ancient sources used in class. Alongside the set essay questions were prompts to use multiple classical and secondary sources, and to bring together sources and information from different topics. The instructions and questions for the set of Roman essay questions are shown in Appendix 1. The marking was conducted by various individuals overall; however, all the marking for the essays included in the dataset was done by the PhD candidate and Graduate Teaching Assistant who led four seminars.

Student engagement with ancient literature was emphasised throughout contact hours, and in the marking criteria which were available to and discussed with students. In the marking criteria, reference was made within each grade classification to varied levels of engagement with the materials studied in and out of class. In class, a range of primary and secondary sources was used to showcase the literature available and illustrate how academics use and incorporate a range of sources into their written work. Each seminar typically relied on one secondary source and two primary sources. Over the course of the term, students will have seen eight different types of ancient (i.e. primary) sources, per the QAA benchmark statement (2014: 10). Seminars relied on key readings and discussion of various sources each week. In lectures, the diversity of sources was taught didactically, though with more focus on content such as key ancient events and political situations. Lectures were given by different full-time academics according to their speciality. 
Overall, the design of the module appeared to demonstrate good alignment between intended learning outcomes, teaching, and assessment (Biggs, 1996). The module was set out in such a way that multiple sources were dealt with and consulted, alongside intended learning outcomes which explicitly informed the students and teachers of the module goals. The assessments provided students with an opportunity to practice and develop the skill of incorporating multiple classical sources.

\section{Materials and Analysis}

The first author analysed student bibliographies in 1500 word essays $(\mathrm{N}=84)$ submitted for the final Roman history and literature assessment on the Egeria University module described above. The aim was to determine how successfully students met the intended learning outcome of incorporating a wide array of sources, including both primary and secondary sources. Each bibliography was inspected for the number of sources used, whether they were classical or secondary sources, the number of classical sources consulted, the number of different ancient source types used, and the number of non-academic sources included. The different types of classical sources have been taken from the learning outcomes in the module description, as well as those described in the UK QAA subject benchmark for classics and ancient history (2014) namely historiographical, biographical, poetry, epic poetry, plays, speeches, and documents dealing with law. This list was expanded to also include ancient personal letters.

\section{Findings}

Most students (70\%) used four to nine sources in their essays, as shown in Figure 1. Figure 2 shows the use of non-academic sources, such as online encyclopedias specific to classical history (e.g. Ancient History Encyclopedia, Livius, and Encyclopedia Britannica) (Fig. 2), indicating that students, for the most, used reliable peer-reviewed sources. 


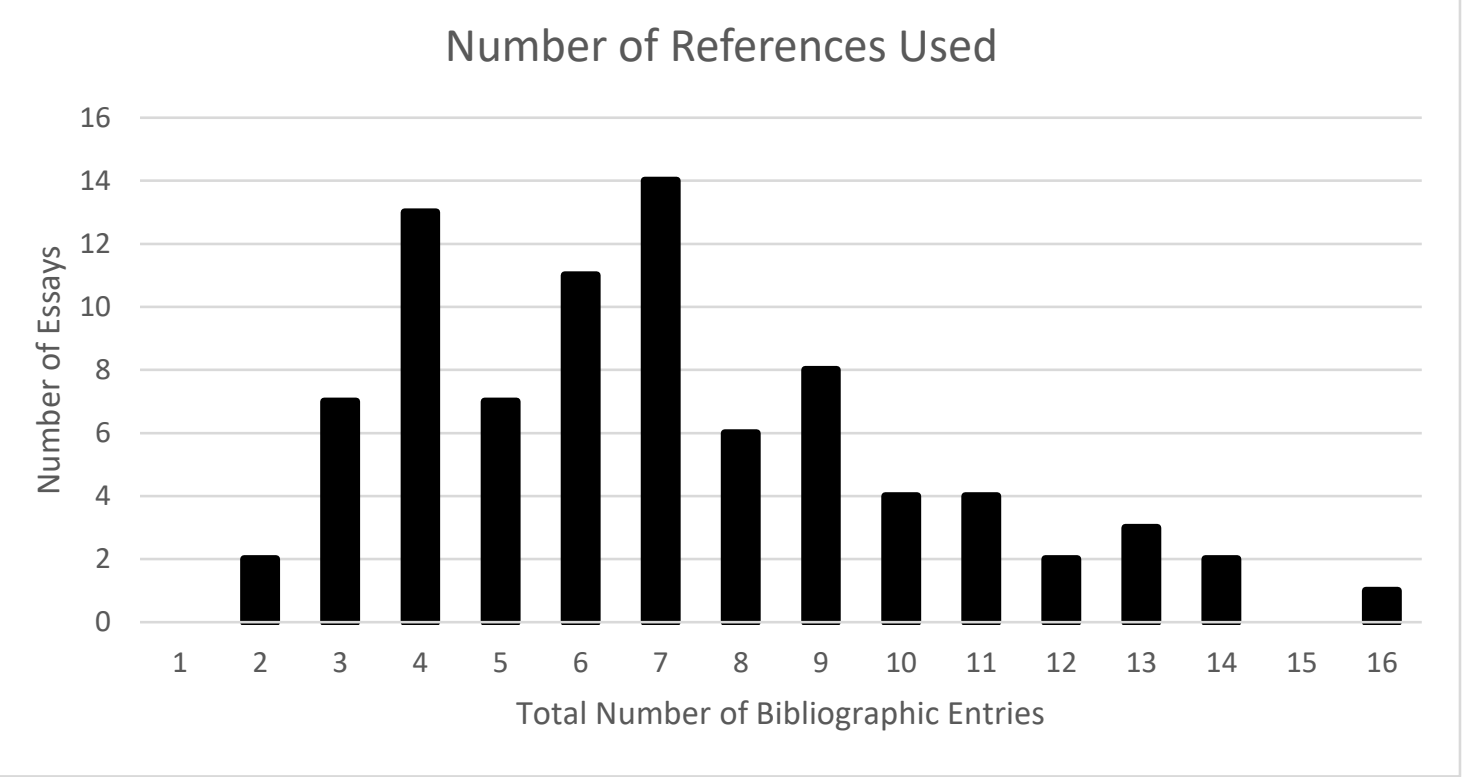

Figure 1: Number of sources students used in final 1500 word essay.

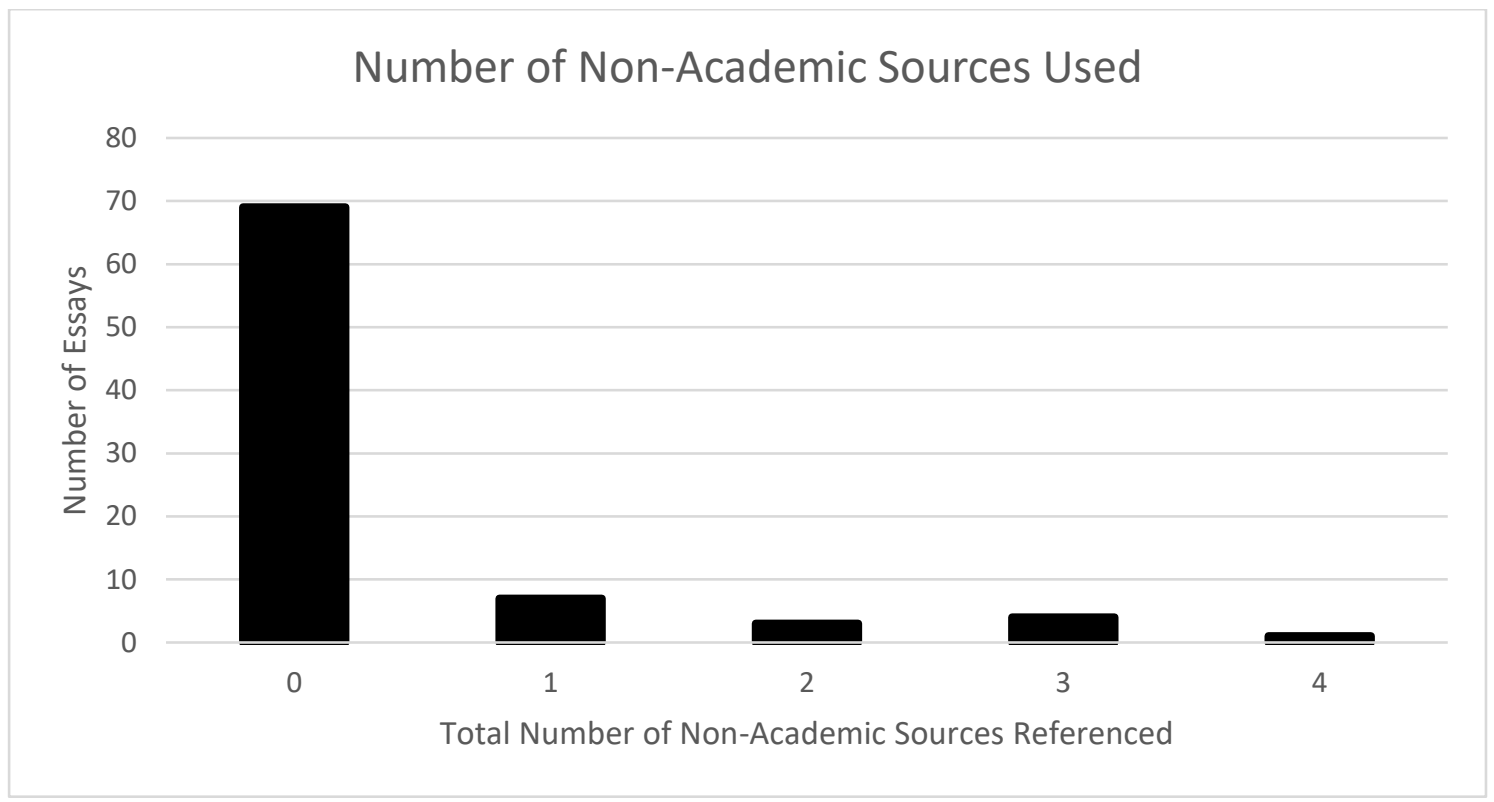

Figure 2: Number of non-academic sources students used in final 1500 word essay.

Figure 3 shows that students used more secondary sources than primary ones. Given that secondary literature is generally used to support the analysis and discussion of surviving 
sources from the Roman period, this finding was not surprising. However, 11 (13\%) of the students did not engage with ancient sources at all, 28 (33\%) students used just one classical source, whilst $19(23 \%)$ incorporated two. Thus two-thirds of students (69\%) used two primary sources or fewer in a 1500 word final essay after two terms of university study.

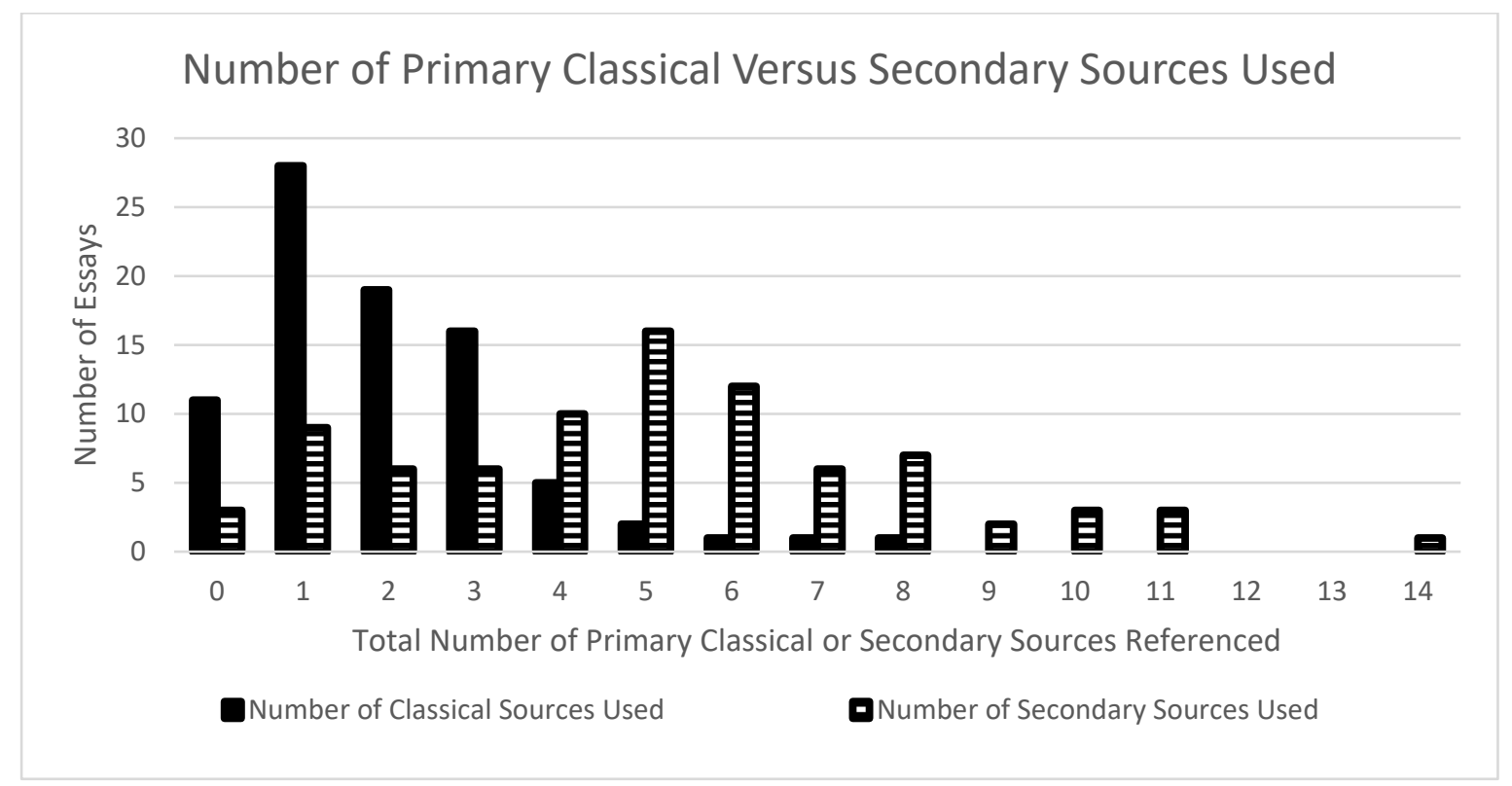

Figure 3: Number of primary classical and secondary sources used in students' final 1500 word essays.

Figure 4 demonstrates the number of different types of sources students incorporated into their essays. A high percentage (56\%) of students did not use more than one type of classical literature in their essays (usually historical narrative or epic poetry), with 32 (38\%) individuals including two. Only $5(6 \%)$ of the students overall drew from three or more types of ancient literature. 


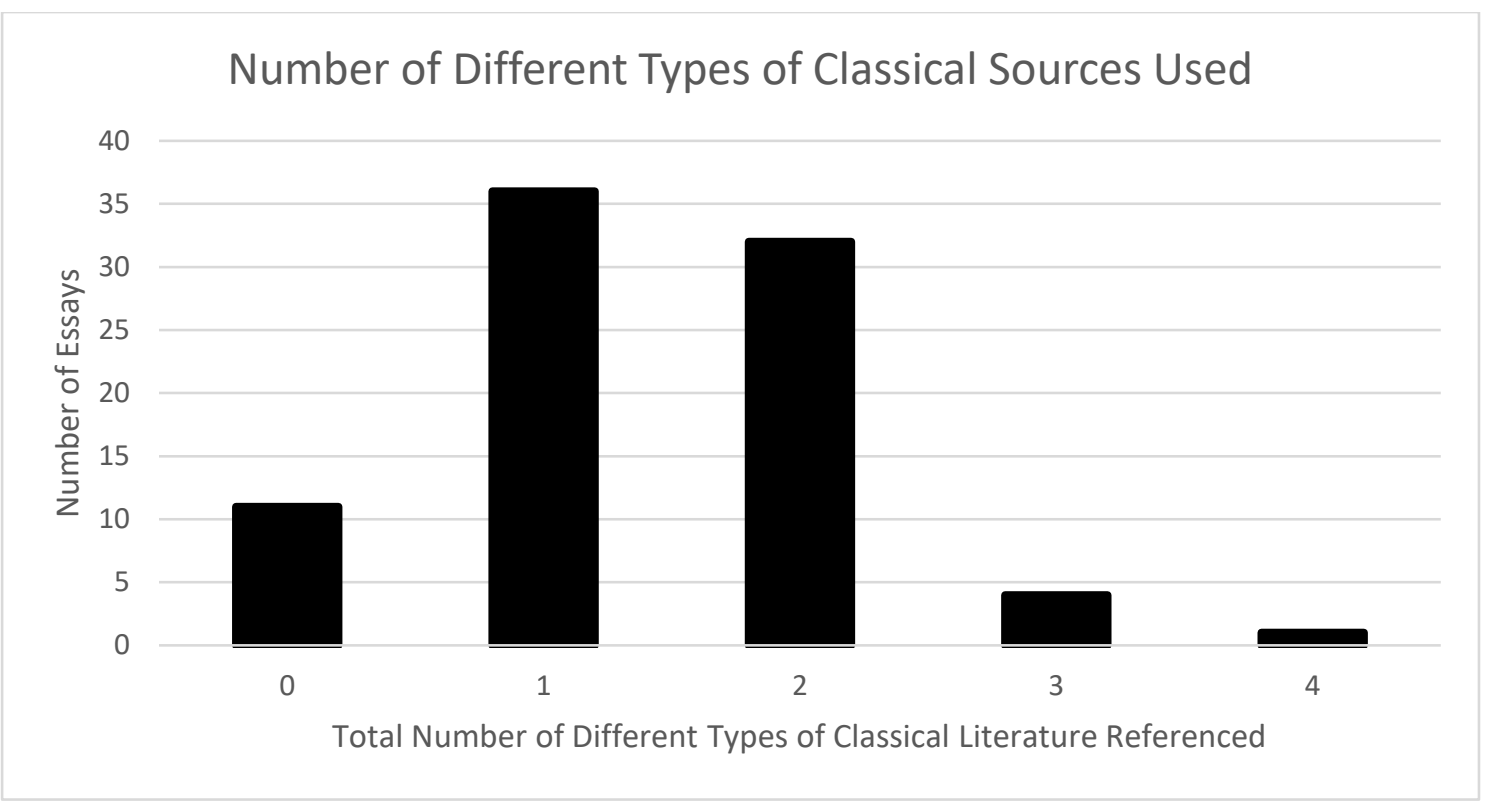

Figure 4: Number of different primary sources used in final essays.

\section{Discussion}

Most students referenced four to nine different sources in their final 1500 word coursework essay at the end of a two term, first-year undergraduate module in classics and ancient history. Most were relying on academic, rather than non-academic sources which is a sign of success for the teaching of the module. However, there was considerable reliance on secondary sources and more than half of the students used only one type of ancient source. Most (94\%) students used fewer than three different types of ancient source. This outcome, for a module specifically intended to teach students the skill of synthesising multiple different types of ancient sources in crafting an interpretation and argument, is disappointing. When students used ancient sources, most used historical narratives or epic poems. These two types of ancient sources are the source types predominantly used in A-level study of classics and ancient history. Furthermore, students who have studied English literature or history at ALevels may also be familiar with those kinds of sources. This finding suggests that more 
attention needs to be paid to helping students appreciate and use other types of sources of which they may have no experience prior to university.

Despite apparently good alignment between intended learning outcomes, teaching, and assessment criteria, students' relatively low engagement with different types of ancient sources suggests either that it was not aligned in the eyes of students (Biggs, 2012) or that the teaching of this particular objective needs to be improved or both. The learning outcomes clearly expressed what is expected of students in the assignments and seminars, though they may not have been understood fully by students. This hypothesis is worth further investigation. The assessments were designed for students to demonstrate those key skills. Assessment criteria were also consistent with those learning outcomes, though they could be made more specific in clarifying the expectation of using multiple sources to support an argument. On balance, we suspect that the teaching itself may have sent the wrong signals to students or may not have allowed them sufficient practice in the core skill.

The Roman section of Egeria's first year core module was split into two main parts: ancient history (event and individual based) and classical literature, with a new topic discussed each week. Thus students focused on one aspect of the ancient world at a time; for example Julius Caesar's political career, Augustus' founding of the Roman Principate, or Virgil's Aeneid. Each week involved students reading relevant ancient sources to evidence events in the past, as well as encourage discussion. This process allowed for an easily understandable progression through the content of the module. However, using specified ancient sources to introduce and discuss certain historic individuals and events may have inadvertently caused students to associate certain types of sources with specific content $-\mathrm{a}$ shortcoming of A-level curricular and assessment regimes noted earlier. Thus students may, quite understandably, think that teaching will replicate their A-level experience (Perry and Allard, 2003). 
In sum, this module trialed a new, integrated approach to teaching skills with content (Booth, 2005: 19; Wilson and Child, 2017: 189), a trend in this field. Integrating skills and content is a desirable goal, but also challenging for teachers who may not be accustomed to explicitly teaching skills. Therefore, we suggest that the teaching itself needs to be reconsidered to help students meet these challenging new higher education expectations. Simply advocating for or even developing apparently-aligned modules (Biggs, 1996) that integrate skills and content (Booth, 2005) may not be sufficient. In the next two sections we offer a substantive reflection on possible ways to move the field forward. We focus on making the thinking processes used by experts in classics and ancient history more explicit to students transitioning to higher education.

\section{Next steps for enhancing teaching practice}

Inspired by work on "decoding the disciplines" in undergraduate history education (Middendorf and Pace, 2004; Pace, 2011), we think a more explicit, theoretical grounding for the process of 'making thinking visible' would be useful to achieve greater success with the type of first year course evaluated in this study. Thus, we rely on the cognitive apprenticeship theory of teaching and learning (Collins et al., 1991) which provides 'a model of instruction that works to make thinking visible', replicating the teaching steps of a traditional apprenticeship within the classroom (Collins et al., 1991: 1). This model is based on research which concerns the process apprentices use when learning a practice: actively learning within a community of practice by observing, questioning, and doing in an environment that explicitly involves the trainee in their learning experience.

A challenge faced by teachers employing this process, however, is the difficulty in making explicit the implicit processes academics use when writing and researching (Austin, 2009: 175). Consistent with history educators (Middendorf et al., 2007; Wineburg, 2001, 
2011), the use of a range of classical source types in interpreting historical events is a key aspect of practising classicists and ancient historians. In classics, the use of primary sources is complicated, though, by the range of types of sources students must analyse from a variety of different sub-disciplines, including archaeology, literature, art, politics, philosophy and law.

The second challenge in applying the model is that traditional apprenticeships occur in their real-world contexts, whereas classroom teaching is estranged from the contexts in which academic writing and research occurs (Austin, 2009: 175; Collins et al., 1991: 3). Thus a goal in seminars might be to create forums that more closely simulate a community of researchers analysing documents together to construct explanations of the past.

Table 1 sets out the six key steps of the cognitive apprenticeship theory (Collins et al., 1991) with brief examples of how a classics and ancient history teacher might apply them when teaching students to use a range of classical source types in essays, research, and arguments. This overall process of making the key cognitive practice of the discipline explicit, then developing applications of this generic model can be applied to a range of discipline-specific pedagogical challenges in higher education, as Collins and colleagues have done in primary and secondary education (1991). We follow the table with a more elaborated example of how teaching might be adapted when guided by this model. 


\section{Key Step Definition \\ Modelling}

The teacher demonstrates a cognitive process, so the learner can conceptualise the steps involved in carrying it out themselves. Modelling includes explicitly revealing the procedures, techniques, and heuristics (rules of thumb) used to complete the work.

Coaching

The teacher coaches students as they engage in the key cognitive processes being trained. Thus students are practicing, in lower risk settings, the same processes as academics in classics use.

Scaffolding /

Fading

The teacher guides students through the more difficult sections of work (scaffolding), and subsequently reduces assistance as students progress (fading).

Articulation

Insofar as thinking is visible only through verbalisation, students need to "think aloud" in order to be coached. Articulation means finding and using the words to describe thought processes and labelling different parts of their work and processes and relations between those parts and the whole task.

\section{Teacher Behaviours}

The teacher explicitly demonstrates, discusses and explains how to find, incorporate, reference, use and combine classical sources. Modelling can be done in a lecture or smaller group seminars when students are more actively involved.

The teacher sets appropriate tasks and design learning environments that enable students to practice using multiple sources and then provides constructive criticism through the provision of hints, diagnosis of problems, feedback, identification of weaknesses and strengths, as well as aiding and encouraging analysis of problems. Coaching can be incorporated into weekly tasks, discussions, and assessments.

The teacher will assist students in carrying out key skills such as completing part of the task for students to then continue, or providing step-bystep checklists, or templates. The teacher will reduce the amount of assistance over time (fading).

The teacher creates opportunities for students to describe how they are approaching a text.

Students could be asked to find/analyse sources for a specific event, theme, or person. Prompts may include asking how sources compare to one another and the advantages of specific approaches. The teacher coaches students based on what and how well students' articulate their processes.

\section{Student Behaviours}

The student will be directed to attend to the processes involved in becoming a classicist and/or ancient historian. They will listen to the teacher, take note of the processes which are demonstrated, and take part through questions about how sources are used to generate content (not just about the content itself).

Students practice the procedures demonstrated in modelling during seminar discussions, set tasks and formative essays. Students will take in the comments of their teachers to further improve their ability at engaging with classical sources.

Thus students actually practice the skills and get feedback on those practice exercises.

Students will begin to use key skills in a structured, guided way before eventually using them autonomously in their individual essays with little or no guidance from teachers.

Students engage in articulation, showing thei approaches to analysing sources, and choosing which ones best tackle the issue they are faced with. For example, students will choose which sources to use, how to approach them, and explain why their chosen processes are better than others. 
Reflection

The student reflects on their processes, comparing their own work to their previous attempts, other students, academics and the experts they read in secondary literature. This process will include identifying strengths, weaknesses, and ways to improve.

Exploration

The student is guided to recognise their learnt processes and think about how they may apply to wider contexts and situations.
Teachers encourage reflection through one-onone discussions, class-wide feedback sessions, and tasks which require reflection and

comparison activities with essays and articles.

Prompts might include: Do other academics use similar or different sources to examine particular events such as the Catilinarian Conspiracy? Are there alternative interpretations of crucial

ancient texts being used for specific hypotheses that can strengthen or challenge your work?

The teacher provides guidance on how learnt skills can be used alongside advanced themes.

Teachers can encourage exploration through the explicit inclusion of modern, innovative theories and themes that demonstrate the breadth of research in the field. Continued emphasis on learning outcomes which encourage the use of sources from multiple topics may aid in the

development of student led exploration.
Students will use answer reflective questions, identifying similarities and differences and strengths and weaknesses. The student will use their findings to incorporate good practice into their own work.

Students will formulate arguments and ideas that bring together a wide range of themes and

sources, incorporating their work into a modern and innovative framework. 


\section{Applying cognitive apprenticeship to a traditional classics course curricular structure}

In this section, we elaborate the brief summary provided in Table 1 to show how the cognitive apprenticeship model could apply to classics teaching. Key constructs of the model appear in italics. First, teachers could provide some explicit instruction about where to find ancient sources, modelling the process. Then, instead of providing students with sources for each event or individual in history, seminar leaders could dedicate a session to the skill of searching for classical sources. That it, they could provide students with a topic such as the representation of the barbarian, requiring students to search for relevant sources. Students will source their own evidence to bring to the seminar, and discussion can focus around what each source contributes to the understanding of the topic. The seminar leader can have backups to fill in any gaps in students' contributions. Doing so makes the seminar more like a community of scholars who are jointly analysing a question, sharing different sources that inform an answer, bringing authentic disciplinary practices into the classroom. As students become actively engaged in sourcing their own evidence and discussing hypotheses in relation to a question, the teacher can coach this performance. Teachers can emphasise the fact that university requires more independent inquiry than previous educational levels, encouraging students to articulate, reflect on and explore their independent thinking processes.

Students would, of course, need gradual training - scaffolding - in carrying out this task. In the first weeks, students could be provided with core materials, but asked to bring one or two additional resources with them. Over time, students would learn where to search for their own sources and the balance between teacher-provided sources and students' independently found sources would shift in the seminars (fading). Through this process, students would be increasingly more active in finding their own sources (exploration), as well as practised in explaining why certain literature has been chosen (articulation). In time, 
students would be able to discuss their sources, not just cite them, demonstrating their development as competent and independent learners who have been successfully taught subject specific skills (Jones, 2018: 229; Wingate, 2007).

Such an approach however, relies upon student effort and willingness to be proactive. This aspect needs to be emphasised at the beginning of the student's university career and embedded early in the creation of their academic identity. Seminar leaders would also have to be adaptable due to the myriad of sources students may bring to class and buy into a process approach to teaching, not just a content focus (Quinlan, 1999). In particular, interacting with novel resources alongside students would force seminar leaders to model the thinking processes that characterise the field, which lies at the heart of the cognitive apprenticeship model.

Applying the model to a redesigned curricular structure: Thematic seminar sessions

The chronological approach of the existing module, particularly when teaching historical events, may have hindered students in making effective use of multiple ancient source types in a single essay. In a museum education context, Lubar argued that a chronological understanding of history directs a certain narrative which represents history as purely a route to the present (2013: 169). A chronological narrative can limit discussion by contributing to an inflexible view of the past which shuts down rather than opens up multiple interpretations.

It may, therefore, be beneficial to alter the way in which lectures and seminars are structured for a first-year undergraduate classical studies and ancient history module. A thematic approach could be adapted and used in the study of classics and ancient history, providing students with the opportunity to bring many types of sources together which relate to key topics such as identity, social class, slavery, power and so forth. As Hubard demonstrated through teaching students art within museums, a thematic approach can allow 
pupils to come at ideas from a multiplicity of different angles (2014: 111). The teaching of art through a thematic approach is also seen in many other UK museums such as The Tate, the Tate Modern, and the National Gallery (Hubard, 2014: 105).

Thematic approaches in workshops and education sessions also occur in museums dealing with the ancient world on themes such as everyday life, Roman and native identity, or money and its use within the Roman Empire (e.g. educational sessions and workshops at the British Museum, Corinium Museum, Museum of London, and Verulamium). Each session uses a wide range of archaeological material, digital content, and different types of ancient and modern literature to explore certain themes. Learners become involved in the process of closely engaging with literature and materials. In the case of Hubard's approach to teaching art, visitors are depicted as becoming active makers of meaning. Through the process of learning in a thematic framework, individuals acquire the skills to confidently interpret other art for themselves (Pringle, 2009). Therefore, the thematic approach may also be suitable for a university degree that explicitly aims to develop students' historical thinking (Quinlan, 1999). It is not clear how widespread a thematic approach is in the teaching of classics; this question warrants further study.

In classics and ancient history at higher education level, using and discussing a diverse range of themes and sources would allow students to practice using ancient source types to tackle key questions, going beyond a focus on facts and conclusions to argument and reasoning. Seminars and lectures that feature a thematic approach must address skills learning early on by modelling the process of searching and reading classical sources through a themed approach, in keeping with the cognitive apprenticeship model.

For example, a week within the module could focus on the study of morals during the Roman period, incorporating historiographical texts, poetry, plays, speeches, law, and biographical work. The lecturer or seminar leader could then model how to draw information 
from each source type, explicitly establishing the key skill and processes for students. As with the previous suggestion, students could then be encouraged to bring sources (articulation), widening the scope of student interest (exploration) and participation within seminars. This approach is similar to the one described above, but expands upon it. Relying on student preferences for which sources they bring for discussion might result in a good range of source types incorporated into lessons, allowing students to engage with preferred evidence as well as compare with those brought by others (reflection). As a result, students would be encouraged to contribute towards a process involving a wide array of sources, challenging their ability to incorporate unfamiliar evidence into their ideas, and thus providing opportunity for academic development. This process will also include coaching from the teachers who would guide discussions and provide feedback, albeit with emphasis on these discussions to become more student-led as time goes on (fading).

Such a thematic approach may require significant restructuring of existing modular content. However, the benefits of using themes to direct student progression may outweigh the pros of a chronological outline of history. A thematic approach also has the advantage in that it encourages an inquiry-based approach, so that the range of sources brought to seminars needs to be discussed individually, as well as linked to one another as a whole. The aim of this process is to create a teaching environment where students develop an awareness and understanding of sources akin to a professional academic. A thematic approach also encourages students to articulate, reflect on and explore by being actively involved in finding, using, and discussing how experts have used a wide range of sources for specific themes - again consistent with the cognitive apprenticeship model.

\section{Next Steps for Further Research}


Further similar studies need to be conducted, echoing the call to action by Heiland and Rosenthal (2013: 15). While it would be useful to continue the exploration of the relationship between other naturally occurring forms of instruction (e.g. skills-based only, thematic) and students' use of multiple sources in classics, such investigations need to look more closely at precisely how source use is taught and understood by students. The cognitive apprenticeship model laid out here provides a framework for analyzing future case studies of instruction.

This paper has laid out possible future directions for teaching to address this core challenge in classics and ancient history. Next steps might involve experimenting with these approaches and testing their effectiveness in terms of students' use of sources, as illustrated in the empirical component of this study. Comparable studies of students in second and third years of university would create a picture of the development of this vital skill over the course of the degree programme. Finally, it would be useful to dig more deeply into how students are using sources, not merely which ones and how many they use (Jones, 2018). Ancient historians do not just cite sources, they use them in particular ways to argue interpretations of historical events. Toward that end, studies using think aloud protocols could illuminate how students' think through a source and incorporate it into their writing as well as examining how students' source use changes over time in response to instruction, as illustrated by Usher (2018). Students' processes could be compared to experts' views to illustrate differences and highlight specific sub-skills that are particularly problematic.

\section{Conclusion}

Students must learn key discipline-specific skills and ways of thinking in higher education, such as effectively finding, analysing and incorporating multiple sources into arguments in the field of classics. Independently using these kinds of skills constitutes part of the challenge of transition between school and university. This study investigated how effectively students 
were able to exercise those skills following an integrated skills and content first year course. The results showed that although students were using scholarly sources, they relied heavily on secondary sources and only one or two primary sources. They tended to use a limited range of different kinds of sources, although use of a wide range of sources was a key objective of the module. While debates may focus on whether to have separate skills-based courses alongside content-focused courses or to integrate skills and content into core modules, we conclude that there needs to be closer attention to how to teach in a way that integrates skills with content. We have used the cognitive apprenticeship model of instruction as an underpinning theory for integrating skills. Our examples show how teaching itself could become more aligned with skills-based learning outcomes and assessment (Biggs, 2012) in an integrated skills-content module for first-year students.

If the aim is to help students think like a classicist or ancient historian, a model of instruction that makes that thinking process visible is required. This model embraces an approach that is authentic to the discipline, engaging students in thought processes and actions that a professional academic within the same area of study would follow. Thus, it may be particularly helpful in the transition from school to university. 


\section{Appendix 1}

Task: Choose one of the following questions to answer.

Remember that you should demonstrate your knowledge of the material covered in the module (think laterally and, if possible, combine material encountered in different weeks) Use further reading (of both primary material and scholarship) to add greater depth to your analysis.

1) Why was the Roman Republic fragile and prone to political instability during the first century BC?

2) What are the similarities and differences between Sulla's and Caesar's dictatorship?

3) What were the importance and legacy of the Catilinarian conspiracy?

4) How was Octavian able to end the Civil Wars and to establish the Principate?

5) What makes the genre of satire stand out in Classical Literature?

6) How did Virgil's epic, the 'Aeneid' shape the image of Augustus?

7) How valuable are Plutarch's 'Lives' as a historical source for the history of the Roman Republic?

8) What makes Ovid's 'Metamorphoses' so powerful? 


\section{References}

Alder E (2016) Becoming a Student of English: Students' Experiences of Transition into the

First Year. Arts \& Humanities in Higher Education 17(2): 185-203.

AQA (2014) GCE AS and A Level Specification, Classical Civilisation. Available at:

https://filestore.aqa.org.uk/subjects/specifications/alevel/AQA-2020-W-SP-14.PDF

AQA (2019) Level 3 Extended Project Qualification (7993). Available at:

www.aqa.org.uk/subjects/projects/project-qulaifications/EPQ-7993

Austin AE (2009) Cognitive Apprenticeship Theory and its Implications for Doctoral

Education: A Case Example from a Doctoral Program in Higher and Adult Education. International Journal for Academic Development 14(3): 173-183. DOI:

$10.1080 / 13601440903106494$.

Baker S (2017) Shifts in the Treatment of Knowledge in Academic Reading and Writing:

Adding Complexity to Student's Transitions Between A-levels and University in the UK. Arts \& Humanities in Higher Education 17(4): 388-409.

Ballinger G (2003) Bridging the Gap Between A Level and Degree. Some Observations on Managing the Transitional Stage in the Study of English Literature. Arts and Humanities in Higher Education 2(1) 99-109.

Biggs J (1996) Enhancing Teaching Through Constructive Alignment. Higher Education. 32: 347-364.

Biggs J (2012) What the Student Does: Teaching for Enhanced Learning. Higher Education Research \& Development 31(1): 39-55.

Booth A (2003) Teaching History at University: Enhancing Learning and Understanding. London: Routledge.

Booth A (2005) Worlds in Collision: University Tutor and Student Perspectives on the Transition to Degree Level History. Teaching History 121: 14-19. 
Briggs ARJ, Clark J and Hall I (2012) Building Bridges: Understanding Student Transition to University. Quality in Higher Education 18(1): 3-21.

Cain A and Ali Baber M (2016) Reflections on Applying Constructive Alignment with Formative Feedback for Teaching introductory Programming and Software Architecture. 2016 IEEE/ACM $38^{\text {th }}$ International Conference on Software Engineering Companion (ICSE-C), 336-345.

Collins A, Brown JS and Holum A (1991) Cognitive Apprenticeship: Making Things Visible. American Educator: The Professional Journal of the American Federation of Teachers 15(3): 6-11.

Ellis D (2008) In at the Deep End? The First Year of Undergraduate English. London: Higher Education Academy Subject Centre for English.

Ferreira J (2018) Facilitating the Transition: Doing More Than Bridging the Gap Between School and University Geography. Journal of Geography in Higher Education. DOI: 10.1080/03098265.2018.1437397.

Gale T and Parker S (2012) Navigating Change: A Typology of Student Transition in Higher Education. Studies in Higher Education 39(5): 734-753.

Gill T (2016) Uptake and Results in the Extended Project Qualification 2008-2015.

Cambridge: Cambridge Assessment.

Goodman PJ (2017) Bridging The Gap: Teaching and Studying Ancient History and Classical Civilisation from School to University. The Journal of Classics Teaching 18(35): 4853.

Heiland D and Rosenthal L (2013) More Than Limited Learning: The Case for Focusing Upon the Disciplines. Arts and Humanities in Higher Education 12(1): 7-19.

Hubard O (2014) Concepts as Context: Thematic Museum Education and its Influence on Meaning Making. International Journal of Art \& Design Education 33(1). 
Jones A (2018) A (Theory and Pedagogy) Essay on the (History) Essay. Arts \& Humanities In Higher Education 17(2): 222-240.

Kift S (2009) Articulating a Transition Pedagogy to Scaffold and to Enhance the First Year Student Learning Experience in Australian Higher Education: Final Report for ALTC Senior Fellowship Program. Queensland: Queensland University of Technology, Australian Learning \& Teaching Council.

Lubar S (2013) Timelines in Exhibitions. The Museum Journal 56(2): 169-188.

McCann M (2017) Constructive Alignment in Economics Teaching: A Reflection on Effective Implementation. Teaching in Higher Education 22(3): 336-348. DOI: 10.1080/13562517.2016.1248387.

Middendorf J, Pace D, Shopkow L and Diaz A (2007) Making thinking explicit: Decoding history teaching. The National Teaching and Learning Forum, 16, (2), 1-4.

OCR (2016) AS/A Level GCE. GCE Classics. Available at:

https://www.ocr.org.uk/qualifications/as-and-a-level/classics-classical-civilisationh041-h441/ (accessed 05/11/2019).

OCR (2018) A Level Specification, Classical Civilisation. Available at: https://www.ocr.org.uk/qualifications/as-and-a-level/classical-civilisation-h008-h408from-2017/ (accessed 05/11/2019).

Perry C and Allard A (2003) Making the Connection: Transition Experiences for First-Year Education Students. Journal of Educational Enquiry 4(2): 74-89.

Pringle E (2009) The Artist-Led Pedagogic Process in the Contemporary Art Gallery: Developing a Meaning Making Framework. International Journal of Arts \& Design Education 28(2): 174-182.

Quinlan KM (1999) Commonalities and Controversy in Context: A Study of Academic Historian's Educational Beliefs. Teaching and Teacher Education 15: 447-463. 
Skinner K (2014) Bridging Gaps and Jumping Through Hoops: First-Year History Students' Expectations and Perceptions of Assessment and Feedback in a Research-Intensive UK University. Arts and Humanities in Higher Education 13.4: 359-376.

The Quality Assurance Agency for Higher Education (QAA) (2014) Subject Benchmark Statement. Classics and Ancient History (Including Byzantine Studies and Modern Greek). Available at: http://www.qaa.ac.uk/en/Publications/Documents/SBS-classics14.pdf (accessed 16 May 2018).

Williamson J and Vitello S (2018) AS Levels Trends 2018: Research Report. Cambridge: Cambridge Assessment.

Wineburg S (2001) Historical thinking and other unnatural acts: Charting the future of teaching the past. Philadelphia: Temple University Press.

Wineburg S (2011) Reading like a historian: Literacy in the middle and high school history classrooms. New York: Teacher's College Press.

Wingate U (2007) A Framework for Transition: Supporting 'Learning to Learn' in Higher Education. Higher Education Quarterly 61(3): 391-405.

Usher N (2018) Learning About Academic Writing Through Holistic Peer Assessment. PhD Thesis, University of Oxford, UK. 